\title{
Desenvolvimento profissional de professores: um quadro teórico
}

\author{
Teacher professional development: a theoretical framework \\ Desarrollo profesional de los docentes: un marco teórico
}

Recebido: 25/10/2021 | Revisado: 01/11/2021 | Aceito: 02/11/2021 | Publicado: 04/11/2021

\author{
Adriana Richit \\ ORCID: https://orcid.org/0000-0003-0778-8198 \\ Universidade Federal da Fronteira Sul, Brasil \\ E-mail: adriana.richit@uffs.edu.br
}

\begin{abstract}
Resumo
Apresenta-se um quadro teórico sobre desenvolvimento profissional docente a partir da sistematização e discussão das principais categorias teóricas subjacentes a este processo, as quais predominam na literatura internacional relacionada à formação de professores. Mediante o objetivo de evidenciar e discutir as dimensões subjacentes ao desenvolvimento profissional de professores procedeu-se uma revisão sistemática de literatura que permitiu constituir um quadro das principais categorias abordadas pelos teóricos relacionados à temática, mais referenciados no Google Acadêmico e com índice h-Scopus superior a 20. A análise qualitativa apontou cinco categorias basilares ao desenvolvimento profissional: conhecimento profissional-subsídios basilares à docência; aprendizagens profissionais-aprofundamento e ampliação de conhecimentos docentes; cultura profissional-valores, hábitos e práticas legitimadas por grupos de professores; dimensão ética da docência-compromisso individual e coletivo com a superação das desigualdades de oportunidades educativas e sociais; mudanças na prática-processos de crítica e modificação das práticas de sala de aula, crenças e disposições de professores.
\end{abstract}

Palavras-chave: Aprendizagens profissionais; Conhecimentos profissionais; Cultura profissional; Mudanças na prática.

\begin{abstract}
We present to outline a theoretical framework on teacher professional development from systematization and discussion of main theoretical categories underpinning this process, which are prevalent in the international research on teacher education. With the aim of highlighting and discussing the dimensions underlying the professional development of teachers, we carried out a systematic literature review that allowed us to form a framework of the main categories addressed by the related theorists related to the teacher professional development, who are most referenced in the Google Scholar and with an h-Scopus index higher than 20. The qualitative analyses reveal five categories underpinning teacher professional development: professional knowledge, which characterizes the basic theoretical subsidies to teaching; professional learning, conceived as a process of improving teacher knowledge on teaching practice; professional culture, values, habits, and practices legitimized by groups of teachers; the ethical dimension of teaching, which designates individual and collective commitment to overcoming inequalities in educational and social opportunities; and changes in the practice, understood as processes of criticism and modification of classroom practices, beliefs, and dispositions of teachers.
\end{abstract}

Keywords: Professional learning; Professional knowledge; Professional culture; Changes in the professional practice.

\section{Resumen}

Se presenta un marco teórico sobre el desarrollo profesional docente a partir de la sistematización y discusión de las principales categorías teóricas que subyacen a este proceso, que predominan en la literatura internacional relacionada con la formación docente. Con el objetivo de resaltar y discutir las dimensiones subyacentes al desarrollo profesional de los docentes, realizamos una revisión sistemática de la literatura que nos permitió formar un marco de las principales categorías abordadas por los teóricos relacionados con el tema, la mayoría referenciados en Google Scholar y con un índice h-Scopus superior a 20. El análisis cualitativo señaló cinco categorías básicas para el desarrollo profesional: conocimientos profesionales - subsidios básicos para la docencia; aprendizaje profesional: profundización y ampliación del conocimiento de los docentes; cultura profesional: valores, hábitos y prácticas legitimados por grupos de profesores; dimensión ética de la enseñanza: compromiso individual y colectivo para superar las desigualdades en las oportunidades educativas y sociales; cambios en la práctica: procesos de crítica y modificación de las prácticas, creencias y disposiciones de los profesores en el aula.

Palabras clave: Aprendizajes profesionales; Conocimientos profesionales; Cultura profesional; Cambios en la práctica profesional. 


\section{Introdução}

A natureza da atividade docente, cuja dimensão central é o ensino, solicita dos professores o engajamento em um processo de desenvolvimento profissional ao longo da carreira (Day, 2001), que lhes oportunize alcançar os objetivos do ensino mediante a realização de práticas de sala de aula qualificadas e bem sucedidas. O conceito de desenvolvimento profissional docente está relacionado ao crescimento do professor no nível pessoal e profissional (Richit, 2020; 2021), envolvendo toda e qualquer atividade ou processo voltado a melhorar o conhecimento, as atitudes, as crenças, as disposições, a compreensão e as ações do professor em seu papel presente ou futuro (Fullan, 1995).

O desenvolvimento profissional de professores, concebido como fenômeno contínuo e dinâmico pelo qual o professor desenvolve-se pessoal e profissionalmente, transcendendo o nível individual para o coletivo (Richit, 2020; Richit \& Tomkelski, 2020), constitui-se em componente central das propostas para melhorar a educação (Guskey, 2002) na medida em que envida esforços para melhorar as escolas (Borko, 2004) e a educação (Guskey, 2002) para além do tempo presente (Fullan, 1990; 1993). O desenvolvimento profissional pode ainda ser enquadrado na procura da identidade profissional, na forma como os professores se definem a si mesmos e aos outros, em que as identidades configuram um complexo emaranhado de histórias, conhecimentos, processos e rituais (Marcelo, 2009).

A temática do desenvolvimento profissional docente, embora tenha se disseminado nas distintas comunidades científicas de educação em todos os continentes nas últimas duas décadas, constitui-se em um conceito parcialmente disseminado em alguns países, a exemplo do Brasil. Além disso, o modo pelo qual este processo é concebido pelos principais autores que se dedicam a explicitar os princípios teóricos que o sustentam, tem revelado alguns aspectos basilares, cuja complementaridade sustenta e orienta o crescimento do professor.

Em um estudo dedicado a examinar as reformas educacionais ao redor do mundo, Little (1993) destaca que o movimento de mudanças educacionais contemporâneas envolve aspectos distintos, tais como as questões fundamentais do processo de escolarização, assim como as concepções de conhecimento e aprendizagem profissional de professores. Nesta direção, Christopher Day propõe uma concepção de desenvolvimento profissional centrada nas aprendizagens profissionais de professores, procurando destacar a natureza dessas aprendizagens e os contextos em que elas ocorrem (Day, 2001), nos quais professores novatos e experientes têm a possibilidade de expandir e elaborar sua base de conhecimento profissional (Borko \& Putnan, 1996; Day, 2005).

Laura Desimone, ao examinar os componentes do desenvolvimento profissional docente, afirma que esse processo circunscreve uma base robusta de conhecimento do conteúdo, envolve aprendizagem profissional ativa, é colaborativo, precisa estar alinhado aos currículos e políticas relevantes e, também, pressupõe tempo suficiente de aprendizagem para os participantes (Desimone, 2009; 2011). Os componentes do desenvolvimento profissional de professores apontados por Laura Desimone são confirmados e expandidos no estudo de Darling-Hammond, Hyler \& Gardner (2017), em face ao qual são apresentados e discutidos aspectos particulares das práticas ativas e colaborativas que sustentam o desenvolvimento docente.

Jean Clandinin, por sua vez, propõe uma discussão sobre os conhecimentos intrínsecos ao trabalho do professor, apontando para uma categoria de conhecimento que se constitui e se desenvolve em estreita relação com a prática (Clandinin, 1985; 1986). Este conhecimento, denominado personal practical knowledge (conhecimento prático pessoal), constitui-se na convergência dos conhecimentos teóricos e práticos da docência, influenciado pelas intenções, características e valores do professor (Clandinin, 1986; 1996). É constituído também mediante a necessidade do professor desenvolver uma linguagem e uma base para sua ação, a qual lhe permite compreender e lidar com as situações da sua prática de acordo com as suas características pessoais e com suas experiências de formação (Clandinin, 1985; Clandinin \& Connelly, 1987). Nesta direção, estudos têm evidenciado uma relação positiva entre o desenvolvimento profissional do professor, as práticas profissionais e os 
resultados de aprendizagem dos alunos (Ball, 1993; Darling-Hammond, 1994; Hargreaves, 1995; Hargreaves, 2003; Day, 2005; Fullan, 2007; Borko, 1986; Hill, 2010, Hobold, 2018, Ferreira, 2020).

Considerando a diversidade de aspectos inerentes ao desenvolvimento profissional predominantes na literatura, este estudo busca responder a seguinte questão: Quais são as dimensões teóricas subjacentes ao processo de desenvolvimento profissional de professores? Para tanto, foram analisados os trabalhos dos principais autores que se dedicam a esta temática, os quais são mais referenciados na literatura internacional e nacional de educação.

Assim, o estudo pretende contribuir com a literatura de educação relacionada ao desenvolvimento profissional de professores ao esboçar um quadro teórico relacionado a esta temática, sistematizando as principais dimensões subjacentes a este processo e explicitando aspectos intrínsecos a cada uma dessas dimensões. Esta sistematização pode favorecer a compreensão dos mecanismos e elementos que influenciam o crescimento pessoal e profissional do professor, apontando caminhos para as discussões e ações futuras sobre formação de professores. Este é, portanto, o principal potencial do trabalho em relação à lacuna acima apontada.

\section{Metodologia}

O estudo, de natureza qualitativa e interpretativa (Erickson, 1986), consistiu em uma revisão sistemática da literatura sobre desenvolvimento profissional de professores, realizada nos meses de janeiro a julho de 2021. A revisão sistemática da literatura consiste em um método de atribuição de significado para amplos corpos de informação e um meio de contribuir para se obter respostas para diversas questões, incluindo para o que serve e o que não serve em uma dada investigação (Petticrew \& Roberts, 2006). A análise qualitativa e interpretativa que realizamos consistiu em uma análise de conteúdo (Bardin, 2003), mediante a qual buscamos evidenciar e discutir as dimensões subjacentes ao desenvolvimento profissional de professores. Assim, procedemos a uma busca por trabalhos relacionados a esta temática, assinados por autores mais referenciados na literatura internacional e nacional. A busca foi realizada na plataforma Google Acadêmico ${ }^{1}$ (Google Scholar) a partir dos descritores boleanos "teacher professional development" e "teacher education", informados separadamente em buscas distintas, a partir dos quais três centenas de trabalhos foram identificados.

Considerando o número de citações dos trabalhos retornados pela busca, que são apresentados em ordem decrescente na referida plataforma, iniciamos a primeira etapa de redução dos autores, que consistiu em identificar os autores mais referenciados no Google Acadêmico na temática do desenvolvimento profissional. Essa etapa foi orientada pelo critério de inclusão: (i) trabalho associado à temática do desenvolvimento profissional de professores; e que se baseou na leitura do título, resumo e palavras-chave de cada trabalho. Finalizada essa etapa, o número de autores relacionados a essa temática aproximava-se de meia centena. Assim, procedemos à segunda etapa da seleção dos autores nos baseando em dois critérios de inclusão/exclusão: (ii) autor com número de citações no Google Acadêmico acima de quinhentos (500); (iii) fator h-scopus acima de vinte (20). Esta última fase da redução foi realizada a partir dos dados da plataforma scopus².

O quadro a seguir explicita o processo de delimitação do corpus empírico do estudo a partir dos critérios de exclusão/inclusão supracitados, por meio do qual delineamos os autores que constituem o quadro teórico esboçado neste trabalho. Os autores mais referenciados no Google Acadêmico na temática do desenvolvimento profissional estão dispostos no Quadro 1 em ordem alfabética crescente por sobrenome. Destes, aqueles com índice h-scopus superior a vinte constituem os autores de base no quadro teórico, conforme indica a última coluna.

\footnotetext{
${ }^{1}$ É um dispositivo virtual de pesquisa, vinculado ao Google, de acesso livre, que organiza e disponibiliza textos completos ou metadados da literatura acadêmica em uma extensa variedade de formatos de publicação.

${ }^{2}$ Scopus é a maior base de dados de resumos e citações de literatura científica revisada por pares ao redor do mundo.
} 
Quadro 1: Processo de delimitação dos autores de base para a constituição do quadro teórico.

\begin{tabular}{|c|c|c|c|c|c|c|}
\hline \multirow[t]{2}{*}{ Autor } & \multirow{2}{*}{$\frac{\text { Google Acadêmico }}{\text { Citações }^{3}}$} & \multicolumn{3}{|c|}{ Scopus } & \multicolumn{2}{|c|}{ Incluído na análise } \\
\hline & & Índice $\mathrm{h}$ & Citações & $\mathrm{N}^{\mathrm{o}}$ documentos & Não & Sim \\
\hline Avallos, Beatrice & 2.089 & 11 & 866 & 32 & $\Delta$ & \\
\hline Ball, Déborah L. & 1.749 & 28 & 7.460 & 54 & & ® \\
\hline Borko, Hilda & 5.816 & 29 & 6.284 & 76 & & \& \\
\hline Clandinin, D. Jean & 658 & 24 & 4.296 & 80 & & \& \\
\hline Crandall, JoAnn & 596 & 3 & 28 & 9 & $\Delta$ & \\
\hline Day, Chistopher & 1.395 & 95 & 35.578 & 273 & & ® \\
\hline Desimone, Laura M. & 4.312 & 24 & 5.933 & 56 & & æ \\
\hline Flores, Maria A. & 1.840 & 19 & 1.741 & 81 & $\Delta$ & \\
\hline Fullan, Michael & 1.445 & 25 & 2.722 & 76 & & æ \\
\hline Guskey, Thomas R. & 4.107 & 20 & 3.339 & 58 & & ® \\
\hline Hammond, Linda D. & 1.179 & 44 & 9.675 & 139 & & æ \\
\hline Hargreaves, Andy & 1.436 & 32 & 5.430 & 96 & & ® \\
\hline Heather, Hill & 823 & 25 & 4559 & 54 & & \& \\
\hline Nóvoa, António & 4.089 & 8 & 402 & 24 & $\Delta$ & \\
\hline Opfer, V. Darleeng & 1.517 & 11 & 810 & 23 & $\Delta$ & \\
\hline Shulman, Lee & 1.143 & 20 & 9.127 & 42 & & 巴 \\
\hline Wayne, Andrew & 824 & 5 & 818 & 6 & $\Delta$ & \\
\hline Zabalza, Miguel & 529 & 1 & 24 & 6 & $\Delta$ & \\
\hline
\end{tabular}

Fonte: Elaborado pela autora a partir dos dados extraídos das plataformas consultadas.

Em síntese, mediante a leitura dos títulos e resumos dos trabalhos retornados pela busca, realizamos a primeira redução, em face a qual delimitamos apenas os trabalhos relacionados ao desenvolvimento profissional de professores dos autores mais referenciados. Em seguida, realizamos uma nova redução pelo maior número de citações dos autores no Google Acadêmico. Por fim, observando o índice h-Scopus de cada autor, chegamos aos seguintes nomes: Deborah Ball, Hilda Borko, Jean Clandinin, Christopher Day, Laura Desimone, Michael Fullan, Thomas Guskey, Linda Darling-Hammond, Andy Hargreaves, Heather Hill e Lee Shulman.

Em seguida, realizamos a análise de trabalhos desses autores, apoiadas em Bardin (2003), buscando evidenciar as dimensões (componentes ou princípios) que sustentam o desenvolvimento profissional docente, segundo a perspectiva de cada autor. A leitura dos trabalhos dos referidos autores foi guiada pelas seguintes questões: (1) qual é a concepção de desenvolvimento profissional docente apresentada? (2) quais princípios/aspectos teóricos sustentam a concepção apresentada?

Por fim, a análise dos trabalhos que constituíram o corpus da pesquisa ${ }^{4}$ evidenciou cinco dimensões/princípios basilares ao desenvolvimento profissional de professores, nomeadamente: conhecimentos profissionais, aprendizagens profissionais, cultura profissional, dimensão ética da docência e mudanças na prática. Tais dimensões constituem as categorias de análise abordadas neste artigo, os componentes do desenvolvimento profissional evidenciados na literatura consultada.

\footnotetext{
${ }^{3} \mathrm{O}$ número de citações indica o trabalho do autor indicado no quadro, na condição de primeiro autor, que menciona um dos descritores de busca ("teacher professional development" ou "teacher education") no título ou no resumo.

${ }^{4} \mathrm{O}$ corpus empírico desse estudo constitui-se dos trabalhos mencionados nas categorias teóricas de análise, que são listados nas referências do artigo.
} 


\section{Dimensões do Desenvolvimento Profissional de Professores}

O percurso analítico performado na constituição deste quadro teórico sobre o desenvolvimento profissional de professores evidenciou algumas dimensões que sustentam esse processo, dos quais a apropriação de conhecimentos basilares à docência é apontada em vários trabalhos. Além disso, os trabalhos analisados destacam diversas categorias de conhecimentos necessários à docência e aspectos particulares que os influenciam.

\section{Conhecimentos profissionais}

O desenvolvimento profissional pressupõe, por parte do professor, a apropriação de conhecimentos basilares à docência, assim como o aprofundamento e ressignificação desses conhecimentos no âmbito das práticas profissionais, processo que perpassa a formação inicial e amplia-se para a trajetória profissional, envolvendo a prática e as atividades de formação continuada vivenciadas pelo professor. Dentre os autores que apontam os conhecimentos profissionais como um dos componentes do desenvolvimento profissional, Lee Shulman, pesquisador norte americano, é o autor de maior destaque, cujas contribuições marcaram as comunidades científicas de educação ao redor do mundo. Em meados dos anos 1980, ao examinar os conhecimentos que sustentam e orientam a prática profissional do professor, Lee Shulman apontou três categorias centrais de conhecimentos: content knowledge ${ }^{5}$, curriculum knowledge e pedagogical content knowledge (Shulman, 1986). Em seguida estas categorias foram complementadas por outras quatro, assim denominadas: general pedagogical knowledge, knowledge of learners and their characteristics, knowledge of educational contexts e knowledge of educational ends (Shulman, 1987).

Para Shulman (1986), o content knowledge refere-se ao conhecimento do conteúdo propriamente dito, isto é, o conhecimento científico sobre o objeto circunscrito pela disciplina de ensino enquanto área do conhecimento. Esta categoria de conhecimento ultrapassa os limites da teoria e do acúmulo das informações fundantes da área, adentrando na questão da organização estrutural da área disciplinar de atuação docente. Para Shulman, além de fornecer subsídios para explicar fatos e conceitos científicos, este conhecimento permite ao professor explicar onde esses fatos ou conceitos se inserem dentro de uma área de estudo e, especialmente, como este corpo de conhecimento se constituiu e qual a sua relevância para a área. Acrescenta que o domínio do conteúdo amplia as possibilidades de intervenção docente, enquanto sua deficiência restringe os caminhos a serem seguidos no ensino, pois compromete a capacidade do professor reconhecer o nível de aprendizagem e as dificuldades dos alunos (Shulman, 1986).

O conhecimento do conteúdo é uma das dimensões do conhecimento profissional do professor privilegiada nos programas e diretrizes formativas em todos os continentes ao redor do mundo. Nos Estados Unidos, por exemplo, esta questão tem sido muito discutida porque estudos têm revelado fragilidades em relação ao domínio do conhecimento do conteúdo por parte dos professores. Sobre isso Ball, Heather e Bass (2005) mencionam que pesquisas têm apontado que o nível de conhecimento do conteúdo de muitos professores de matemática estadunidenses é limitado, porque as oportunidades de aprender matemática têm sido desiguais e muitas vezes inadequadas e insuficientes. Assim, problematizam que o domínio do conhecimento da matemática pelo professor é fundamental para sua capacidade de usar adequadamente materiais de ensino, para avaliar o progresso dos alunos e fazer julgamentos sobre apresentação, ênfase e sequência de ensino (Ball, Heather, \& Bass, 2005). Em outras palavras, argumentam que a qualidade e eficiência do ensino de matemática dependem do

\footnotetext{
${ }^{5}$ Optamos por preservar a denominação original apresentada por Shulman como forma de assegurar a fidedignidade do quadro teórico esboçado. Uma tradução possível para estas sete perspectivas de conhecimentos profissionais, frequentemente adotada nas produções brasileiras, é, respectivamente, conhecimento do conteúdo, conhecimento do currículo, conhecimento pedagógico do conteúdo (ou conhecimento didático), conhecimento da pedagogia geral, conhecimento dos aprendizes e suas características, conhecimento dos contextos educacionais e conhecimento dos fins da educação.
} 
conhecimento dos professores sobre o conteúdo disciplinar (Ball, 2000; Hill, \& Ball, 2004; Hill, Rowan, \& Ball, 2005; Hill, 2012).

O pedagogical content knowledge define o conhecimento que circunscreve a dimensão da didática, ou seja, o repertório de formas, estratégias e representações que o professor precisa lançar mão para explicitar o content knowledge (Shulman, 1986). Este conhecimento, segundo o autor, requer que o professor tenha clareza dos graus de dificuldade dos conteúdos, daquilo que torna determinado conteúdo (ou tópico) mais fácil ou mais difícil de ser ensinado e assimilado. Considera que esta dimensão do conhecimento profissional precisa ser a mais ampla possível, pois os alunos nunca são os mesmos, tampouco se apresentam como tábulas rasas ao início de qualquer atividade pedagógica. Os alunos não são uniformes: apresentam distintas bagagens pregressas de conhecimentos, diferentes potenciais de aprendizagem e dificuldades (Shulman, 1986; 2004).

O curriculum knowledge constitui-se como a base de conhecimento sobre o amplo espectro de programas e materiais didáticos projetados especificamente para ensinar determinados conteúdos e em diferentes níveis de ensino. Assim concebido, abarca o domínio dos materiais e dos programas que servem como "ferramentas para o ofício" do professor, pois o ensino de uma disciplina ou conteúdo não é um fim em si mesmo, mas um veículo a serviço de outros fins (Shulman, 1986).

Segundo Shulman, este conhecimento coloca-se como forma de equilibrar a tensão recorrente entre conteúdo e didática, em que geralmente o foco do ato de ensinar tende a ficar em um dos dois lados, como demonstrado pelo autor por meio do escrutínio da oposição entre conteúdo científico e pedagogia desde as universidades medievais até correntes modernas de pensamento pedagógico (Shulman, 1986). Essa categoria está relacionada à capacidade do professor transformar o conhecimento do conteúdo da disciplina de uma forma que o torne interessante e compreensível para seus alunos (DarlingHammond, Hyler, \& Gardner, 2017). É a partir do conhecimento curricular que teoria e prática se articulam, embasando a prática profissional do professor.

O desenvolvimento do curriculum knowledge envolve os fundamentos construídos na formação inicial e pressupõe aprendizagens profissionais ao longo da carreira, mediante atividades de planejamento e intervenção em sala de aula, que se constituem em contextos para análise, discussão, reflexão e proposição de práticas e materiais de ensino. Além disso, essa categoria fornece subsídios para discussões teoricamente embasadas e orientadas sobre como os recursos de ensino e materiais do currículo educacional podem promover a aprendizagem dos alunos, constituindo-se em dispositivo cognitivo que sustenta e orienta a prática do professor (Desimone, 2011). Assim, o conhecimento do currículo promove o equilíbrio na tensão entre as orientações fornecidas pelo currículo e as escolhas realizadas pelo professor.

Nesta direção, ao elaborar um modelo teórico sobre os conhecimentos necessários ao professor de Matemática, Deborah Ball e Heather Hill, em parceria com outros pesquisadores, enfatizam duas categorias de conhecimento apresentados por Shulman: o content knowlegde e o pedagogical content knowledge, conforme figura abaixo. 
Figura 1: Modelo teórico dos conhecimentos do professor.

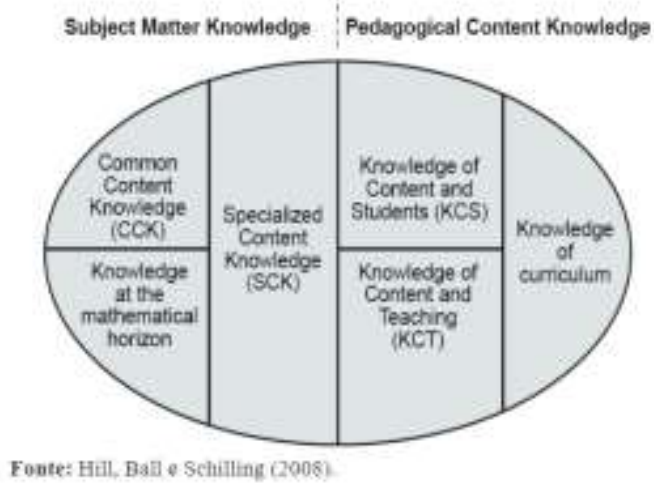

De acordo com a figura, o content knowlegde ou subject matter knowledge foi subdividido em duas subcategorias: conhecimento especializado do conteúdo e conhecimento do conteúdo, sendo que este último foi desdobrado em dois aspectos - common content knowledge e knowledge the mathematical horizon (conhecimento comum do conteúdo e conhecimento no horizonte matemático). O pedagogical content knowledge foi subdividido em conhecimento de conteúdos e estudantes, conhecimento de conteúdos e ensino, bem como o conhecimento do currículo. Esse modelo tem implicações nas perspectivas de desenvolvimento profissional de professores predominantes na literatura sobre desenvolvimento profissional (DarlingHammond, Hyler, \& Gardner, 2017), na medida em que enfatiza a dimensão do conhecimento específico, abrangendo os fundamentos científicos do campo do conhecimento em questão, o conhecimento específico a ser ensinado e como ensiná-lo, assim como o conhecimento do conteúdo que está no horizonte.

Apoiada em Shulman, ao problematizar os conhecimentos necessários ao ensino visando à aprendizagem dos alunos, Darling-Hammond (1999) enfatiza que o professor precisa conhecer de maneira flexível e profunda o conteúdo da disciplina a ensinar para, assim, levar os alunos a estabelecerem trajetórias de aprendizagem coerentes, relacionando ideias e conceitos e identificando equívocos conceituais. Considera, portanto, que esta base fornece uma fundamentação para o conhecimento pedagógico do conteúdo, o qual possibilita ao professor tornar as ideias compreeensíveis aos alunos. Em resumo, os professores precisam compreender como as ideias ou fatos se relacionam dentro do campo do conhecimento, entre campos do conhecimento e com eventos da vida cotidiana (Shulman, 1987; 2004).

O general pedagogical knowledge circunscreve os princípios e estratégias gerais de condução e organização da aula, que vão além da disciplina, de forma que o desenvolvimento de estratégias e abordagens de ensino e aprendizagem precisa acontecer de maneira fluída e dinâmica, norteada por objetivos de aprendizagem bem definidos. Esta dinâmica, assim organizada, favorece a construção do conhecimento, mitigando dificuldades dos alunos, tais como a compreensão de conceitos e conteúdos e a capacidade de relacionar o conhecimento com a realidade. Nesta perspectiva, a docência requer do professor uma preparação didático-pedagógica diferenciada, solicitando o envolvimento em processos de formação continuada e permanente (Shulman, 1987).

Knowledge of learners and their characteristics. Esta categoria de conhecimento profissional é destacada na abordagem de alguns autores referidos nesse quadro teórico. Para Shulman (1987), o ensino é influenciado pela interação entre professor e alunos, de modo que o professor precisa conhecer os alunos, suas características físicas e psicológicas. Ao analisar o modo como o ensino é influenciado pelo contexto e pelos sujeitos envolvidos, Day (2001) considera que há vários fatores que interferem na prática do professor, tais como o desempenho dos alunos e a composição e tamanho das turmas. Day (2001) aponta três conhecimentos que informam a prática do professor, nomeadamente, conhecimento de si próprio, conhecimento da 
situação e conhecimento do aluno. Segundo Christopher Day, esses conhecimentos interagem entre si e influenciam a pedagogia e o currículo forjados e desenvolvidos em cada aula.

Em uma perspectiva similar, Borko (2004) destaca que além de conhecer profundamente o conteúdo a ensinar, o professor precisa conhecer os alunos e o modo com pensam sobre aquele conteúdo ou assunto, sobre suas estratégias para resolver problemas e suas dúvidas e equívocos conceituais. Acrescenta que os modelos teóricos socioculturais predominantes na educação matemática têm se baseado no contexto da sala de aula e em modelos de participação em atividades de aprendizagem. Estas perspectivas têm favorecido o entendimento de como os alunos aprendem por meio da participação em atividades de sala de aula (Borko, 2004; Borko \& Putnan, 1996).

$\mathrm{O}$ knowledge of educational contexts é a categoria de conhecimento profissional que abrange desde o aspecto micro, como o funcionamento do grupo, da turma e da escola (Day, 2001; Clandinin, 2000), até o aspecto macro, como a organização, gestão e funcionamento escolar, as políticas educacionais, a dinâmica de interação entre os agentes escolares, assim como o caráter das comunidades e culturas (Hargreaves, 1995; Fullan, 1995). Essa consciência sobre a conjuntura micro e macro, segundo estes autores, baliza a operacionalização do ensino, favorece a assunção de maior compromisso com a instituição, a comunidade e a sociedade em geral, contribuindo para a melhoria da educação.

O knowledge of educational ends circunscreve os objetivos, as finalidades e os valores educacionais, e seus fundamentos filosóficos e históricos. Envolve, também, a consciência de quais objetivos, finalidades e valores norteiam o ensino, os quais têm fundamentos filosóficos e históricos, estando manifestos, implícita ou explicitamente, no currículo e na cultura escolar. Essa categoria circunscreve também a capacidade de compreensão das necessidades e perspectivas da realidade dos alunos e da comunidade na qual a instituição escolar está inserida. Shulman diz que a docência é uma atividade por meio da qual o professor busca equilibrar os objetivos do ensino, promover uma prática qualificada e orientada por finalidades educativas e sociais mais alargadas, as quais pressupõem igualdade de oportunidades e equidade entre alunos de diferentes históricos e culturas (Shulman, 1987; 2004).

Além disso, o professor precisa conduzir o ensino apoiado na perspectiva do desenvolvimento do aluno, reconhecendo que este não constitui um ser sem concepções prévias e que precisa desenvolver-se intelectual e culturalmente (Shulman, 1987). Para tanto, é necessário conhecer a organização e os princípios fundamentais dos programas escolares, a inserção do conteúdo e da disciplina na formação, a repercussão e as contribuições da educação para o aluno. Day (2001) sublinha que a escola não é apenas um espaço no qual os professores têm a responsabilidade de mediar os valores decorrentes das experiências de vida dos alunos, ela [a escola] existe num quadro de valores e em contextos socioeconômicos competitivos, para os quais também contribui.

Complementando a discussão sobre as categorias de conhecimentos necessários à docência, Shulman apresenta as fontes que as subsidiam. Segundo ele, as fontes constituem os percursos na formação do professor, que vão desde a formação acadêmica na disciplina a ensinar, passando pelas estruturas e materiais pedagógicos, pela investigação sobre aspectos que perpassam o processo de ensino e o aprender, os agentes individuais e coletivos envolvidos, alcançando a experiência (sabedoria) estabelecida pela prática profissional. A partir destas fontes, o professor tem a oportunidade de apropriar-se dessas diferentes categorias de conhecimentos (Borko \& Putnan, 1996; Clandinin \& Connelly, 1996; Darling-Hammond, 2005; Hill \& Ball, 2005; Hill, Rowan, \& Ball, 2005), avançando em seu processo de desenvolvimento pessoal e profissional.

Em síntese, o desenvolvimento profissional pressupõe um conhecimento amplo e profundo sobre o conteúdo a ser ensinado, porque sem este conhecimento do assunto (conteúdo) o professor provavelmente não terá o conhecimento necessário de que precisa para ajudar estudantes em seu percurso de aprendizagem (Ball, 1993; Hill; 2010; Hill, 2012). Entretanto, conhecer bem um assunto não é suficiente para ensiná-lo. O professor precisa desenvolver conhecimentos sobre como ensiná- 
lo, assim como dos distintos elementos que interferem nessa prática, tal como os alunos, os contextos (Ball, Thames, \& Phelps, 2008), as finalidades e objetivos da educação, entre outros.

\section{Aprendizagens profissionais}

Ao assumir a perspectiva teórica da aprendizagem como um processo interativo e dinâmico (Clandinin, 1987; Borko, 2004), compreendemos que o envolvimento proativo do professor em distintas atividades relacionadas ao ensino, incluindo a própria atividade de ensinar, oportuniza-o a concretizar aprendizagens profissionais distintas. Nossa compreensão encontra respaldo em Christopher Day, cuja concepção de desenvolvimento profissional atribui centralidade às aprendizagens profissionais realizadas pelo professor ao longo da carreira. Segundo ele, o desenvolvimento profissional envolve as experiências espontâneas de aprendizagem e as diversas atividades planejadas e concretizadas para o crescimento individual e do grupo, as quais favorecem mudanças na qualidade do ensino em sala de aula (Day, 2001). É o processo pelo qual

os professores, enquanto agentes de mudança, reveem, renovam e ampliam, individual ou coletivamente, o seu compromisso com os propósitos morais do ensino, adquirem e desenvolvem de forma crítica, juntamente com as crianças, os jovens e os colegas, o conhecimento das destrezas e a inteligência emocional, essenciais para uma reflexão, planificação e prática profissionais eficazes, em cada uma das fases das suas vidas profissionais (Day, 2001, p.20).

Os estudos de Day propiciam, segundo Hargreaves (2003), uma visão alargada da aprendizagem profissional de professores, porque têm se debruçado a explicitar quais aprendizagens são realizadas pelo professor e compreender como, quando e como estas aprendizagens ocorrem. Sobre isso, Fullan (1995) diz que as aprendizagens profissionais dos professores são concretizadas desde as primeiras experiências profissionais, alargando-se para toda a trajetória profissional dos professores em vista da natureza dinâmica e complexa dos contextos em que atuam.

Em uma perspectiva complementar, as pesquisadoras norte-americanas Hilda Borko, Heather Hill e Linda DarlingHammond também propõem uma compreensão de desenvolvimento profissional associada ao conceito de aprendizagem profissional. Darling-Hammond (1997) define desenvolvimento profissional como aprendizagem profissional estruturada, que resulta em mudanças nas práticas dos professores e melhoria nos resultados de aprendizagem dos alunos. Darling-Hammond, Hyler e Gardner (2017) concebem a aprendizagem profissional como o resultado de atividades realizadas externamente a profissão quanto de atividades incorporadas ao trabalho cotidiano, as quais fornecem subsídios para aumentar o conhecimento do professor, para modificar a sua prática profissional e apoiar a aprendizagem dos alunos.

Corroborando aos estudos de Heather Hill e Linda Darling-Hammond, Hilda Borko (2004) pontua que as aprendizagens do professor decorrem de muitas situações da prática, tais como as salas de aula, a comunidades escolares, os programas e atividades de formação continuada, influenciadas, segundo Borko e Putnan (1996), pelas características do professor e dos contextos profissionais. Elas podem emergir no contexto das interações cotidianas com os pares, do planejamento e concretização das ações de ensino, bem como das ações formais. E estas aprendizagens, por sua vez, favorecem modificações nas práticas dos professores e promovem melhorias na aprendizagem dos alunos (Darling-Hammond, 1997; 2000) e escolas (Borko, 2004).

Em um estudo dedicado a definir o desenvolvimento profissional, Darling-Hammond, Hyler e Garder (2017) destacam que esse processo apoia-se em princípios a partir dos quais o professor concretiza aprendizagens profissionais. Primeiramente, destacam que o processo é focado no conteúdo, concentrando-se em estratégias de ensino associadas a um conteúdo curricular específico como forma de apoiar a aprendizagem do professor no contexto da sala de aula. Inclui um foco 
intencional no desenvolvimento de currículos específicos de disciplinas e pedagogias em áreas como matemática, ciências ou alfabetização.

Incorpora a aprendizagem ativa na medida em que envolve os professores na concepção e experimentação de estratégias de ensino, que lhes oportunizam realizar aprendizagens profissionais de maneira similar a aprendizagem planejada para os seus alunos. Para isso, pressupõe recursos autênticos, atividades interativas e outras estratégias para promover aprendizagem profissional contextualizada e incorporada. Oferece suporte à colaboração, porque proporciona espaço para os professores compartilharem ideias e colaborarem na aprendizagem mútua, geralmente em contextos de trabalho. Ao trabalhar colaborativamente, os professores podem constituir comunidades de aprendizagem com potencial para modificar positivamente a cultura profissional e o ensino em todos os níveis, departamento, escola ou distrito (Darling-Hammond, Hyler, \& Gardner, 2017).

Além disso, esse processo baseia-se em modelos de prática bem sucedidos. Os modelos curriculares e de ensino fornecem aos professores uma visão clara de como são as melhores práticas. Os professores podem ver modelos que incluem planos de aula, planos de unidade, exemplos de trabalhos dos alunos, observações da prática de colegas e vídeos ou casos escritos de ensino. Fornece formação e suporte especializado pelo fato de envolver o compartilhamento de conhecimentos sobre o conteúdo e as práticas baseadas em evidências, com foco diretamente nas necessidades individuais dos professores. A aprendizagem profissional oferece feedback e reflexão, pois frequentemente fornece tempo integrado para os professores pensarem, receberem sugestões e fazer mudanças em sua prática, facilitando a reflexão e solicitando feedback. O feedback e a reflexão ajudam os professores a se moverem em direção às visões especializadas da prática. Tem duração sustentada, visto que o desenvolvimento pressupõe tempo adequado e suficiente para o professor aprender, praticar, implementar e refletir sobre novas estratégias que favorecem mudanças em sua prática (Darling-Harmmond, Hyler, \& Gardner, 2017). As autoras evidenciam que a aprendizagem profissional, assim concebida, incorpora a maioria ou todos esses elementos, favorecendo, por conseguinte, a aprendizagem dos alunos. Entretanto, as aprendizagens profissionais dependem da constituição de coletivos estruturados e comprometidos com o crescimento da equipe, coletivos esses que incentivem o aprendizado por meio de atividades de discussão sobre o currículo e modos de operacionalizá-lo, favorecendo o desenvolvimento de mudanças curriculares (Darling-Hammond, Hyler, \& Gardner, 2017).

Em uma perspectiva similar, Fullan (1995) adota um conceito de desenvolvimento profissional que inclui a aprendizagem a partir da experiência, que pode ser individual e sem ajuda externa ou da partilha de experiências com os pares. E no contexto dessas aprendizagens, pela convergência de várias aprendizagens (dimensão teórica, dimensão experiencial, dimensão afetiva e outras), conhecimentos prévios são aprofundados e novos são desenvolvidos (Clandinin \& Connelly, 1996) à medida que o professor os contextualiza e os confronta na prática cotidiana, embasando suas ações (Clandinin, 1985; 1986), modificando sua prática (Fullan, 1995; 1997). Portanto, a aprendizagem profissional efetiva pode ajudar o professor a delinear estratégias necessárias e adequadas para desenvolver as capacidades dos alunos (Darling-Hammond, 2000; 2001).

\section{Dimensão ética da docência}

Segundo Andy Hargreaves, o desenvolvimento profissional diz respeito não apenas a uma curiosidade intelectual desapegada (despojada) ou uma atividade legalmente regulamentada. É também foco de um propósito missionário e desejo apaixonado (Hargreaves, 1995; Day, 2006), e um compromisso moral e ético (Fullan, 1995).

Embora a literatura sobre desenvolvimento profissional docente, em especial sobre os conhecimentos e demais componentes que sustentam a docência, sofreu um crescimento nas últimas quatro décadas, os estudos e produções relacionados à dimensão moral e ética da docência representam um número ainda pequeno (Fullan, 1995; 2007). Hargreaves 
(1995) defende que a teorização sobre o desenvolvimento profissional de professores deveria abarcar outros aspectos, tais como o papel e os propósitos morais do ensino, a potencial tomada de consciência sobre o papel da educação e a responsabilidade dos agentes envolvidos, a acuidade do processo educativo, as relações entre os professores e os modos coletivos de trabalhar. Fullan (1993), por sua vez, acrescenta que o professor, cotidianamente, precisa apreciar e praticar os princípios éticos e responsabilidades legais do ensino como uma profissão.

A ética profissional, aqui concebida como a postura de respeito, valorização e dignificação das pessoas em todos os seus papeis sociais, que fundamenta e orienta os processos educativos, abrange algumas dimensões fundamentais, tais como o reconhecimento e o compromisso da educação como um direito humano (Day, 1999; 2001), que vai além da dimensão da legalidade e da obrigação do poder público. A educação e a formação do aluno são também um compromisso e uma responsabilidade individual do professor (Desimone, 2009; Fullan, 1995). Ou seja, a docência é o modo pelo qual o professor concretiza sua função social, transcendendo a defesa ao direito a educação por parte do aluno, concretizando uma educação que traduz objetivos escolares e o currículo em ações comprometidas com o acesso ao conhecimento, o desenvolvimento de capacidades culturais e intelectuais e, especialmente, com a promoção da liberdade de a justiça social (Fullan, 1990; 1994). Esses propósitos, que tem por princípios a equidade, igualdade, justiça e democracia, transitam da dimensão do compromisso coletivo (finalidade da educação) para o compromisso individual (propósito moral do professor e da sua ação) (Fullan, 1985; $1993 ; 1995)$.

Desimone (2009) acrescenta que a dimensão ética da docência caracteriza-se, também, como atividade educativa, a qual se apoia na premissa de que a ética no ensino não é uma abordagem alternativa ao trabalho do professor e não é apenas um fator externo na regulação das atividades educacionais. Atividades educativas assim orientadas favorecem o desenvolvimento de disposições, pensamento crítico e reflexão social e ética (Day, 2001, 2005) dos alunos, ao mesmo tempo em que oportunizam ao professor aprimorar as disposições individuais em relação à prática profissional e das comunidades escolares enquanto coletivo.

A dimensão ética da docência prima pelo desenvolvimento intelectual dos alunos, pela realização de propósitos educacionais e morais (Day, 2001; 2006) e o cultivo de virtudes, mediante práticas profissionais balizadas por virtudes e princípios éticos e morais da profissão (Fullan, 1993; 1995). Circunscreve, ainda, ações mais imediatas do cotidiano do professor, tais como a seleção do currículo e dos dispositivos de avaliação, a seleção e gestão dos recursos de ensino, por meio dos quais o professor concretiza sua prática profissional, por meio dele, o seu propósito moral. A ética profissional é, portanto, o meio pelo qual o professor toma consciência de que a sua prática profissional é uma atividade interativa, dinâmica e flexível, voltada para o coletivo e comprometida com os interesses e necessidades desse mesmo coletivo.

Assim, o desenvolvimento profissional pressupõe a compreensão, por parte dos professores, de que o ensino e a educação, precisam ser direcionados a todos (Fullan, 1985), ao mesmo tempo em que precisam concretizar a sua finalidade social mediante a superação dos preconceitos e das desigualdades que historicamente marcam os processos de ensino e aprendizagem e as oportunidades de desenvolvimento das pessoas. Este aspecto, de acordo com Shulman (1986), perpassa os valores, estatutos e práticas profissionais dos professores, caracterizando a dimensão ética e moral da docência e da educação. Hargreaves (1995, p.26) ressalva, entretanto, que "nenhuma dessas dimensões pode por si só apreender tudo o que é importante. O que realmente interessa e a interação e a integração entre elas".

Nesta direção, consideramos necessário ao professor apoiar e orientar sua prática profissional em uma concepção de docência em que a dimensão ética constitua um elemento intrínseco ao processo educativo (Clandinin \& Connelly, 1988), a partir da qual seja possível concretizar uma educação de qualidade, justa e comprometida com a superação das desigualdades de oportunidades. 


\section{Cultura profissional}

Outra dimensão subjacente ao desenvolvimento profissional diz respeito aos elementos que estão presentes nas culturas profissionais de professores, tais como a maneira pela qual os profissionais se relacionam entre pares e com as situações inesperadas, como se percebem e interagem no contexto profissional, como desenvolvem o currículo, como são encorajados a experimentar mudanças na prática, etc. A cultura profissional têm sido evidenciada em estudos dos autores aqui apresentados, com destaque para Andy Hargreaves, que inaugurou a discussão sobre o conceito de colaboração profissional em contextos educativos nos anos de 1990.

Andy Hargreaves, ao examinar as estruturas, processos e conteúdos das escolas, destaca que as culturas profissionais de professores constituem-se de comportamentos e práticas, modos de agir nas escolas e de interagir com os alunos e colegas. Assim, define as culturas profissionais como o conjunto de valores, hábitos e práticas assumidas nos grupos de professores diante das situações cotidianas (Hargreaves, 1995). Acrescenta que a perspectiva cultural em que as culturas profissionais estão inseridas apoia-se nas relações humanas, pois esta perspectiva parte do pressuposto de que em qualquer organização existe uma cultura partilhada. Para o autor, a cultura sobre as relações humanas consiste em "uma perspectiva que põe em relevo aquilo que é possuído e partilhado em comum nas relações humanas: os valores, os hábitos, as normas e as crenças, isto é, o conteúdo partilhado das culturas dos professores" (Hargreaves, 1995, p. 213). Em síntese, as atitudes e crenças sobre o ensino em geral são amplamente derivadas da experiência cotidiana em sala de aula (Clandinin, 1986; Hill, 2012) ao mesmo tempo em que as práticas profissionais cotidianas são influenciadas pela cultura profissional instituída nas instituições (Fullan, 1995).

Portanto, as culturas profissionais docentes precisam ser compreendidas em termos de crenças, valores, comportamentos e práticas cotidianas, contemplando as disposições e ações dos professores (Day, 2001; 2005). Ao problematizar a temática da colaboração nas pesquisas em educação, Fullan (1995) esclarece que para os pesquisadores desta área interessa investigar as culturas profissionais docentes centradas nas interações entre colegas, na realidade coletiva dos professores nas escolas, enquanto um grupo social e não nas características individuais de cada professor.

Nesta direção e buscando melhor compreendermos os tipos de culturas profissionais docentes, recorremos a Hargreaves (1995), para o qual o individualismo, a colegialidade artificial e a balcanização são culturas que representam as relações profissionais existentes nas instituições de ensino. Estas culturas apresentam limites e possibilidades para o desenvolvimento profissional do professor, e consequentemente, para a mudança da prática. Hargreaves (1995) propõe outra forma de cultura profissional: a cultura da colaboração.

A cultura de colaboração, de acordo Hargreaves (1995; 2003), baseia-se no diálogo e na ação entre colegas de trabalho, nas decisões partilhadas e no apoio mútuo. Em contextos de colaboração, os professores são encorajados a diversificar as estratégias de ensino e, assim, correr riscos, enfrentar mudanças e refletir sobre a própria prática. Além disso, a cultura de colaboração promove o crescimento profissional e assegura efetivamente a mudança educacional (Hargreaves, 1993; 1995), pois a colaboração não se justifica por si própria: ela é um meio para se atingir um fim mais nobre: uma aprendizagem mais rica e mais significativa dos alunos (Day, 1999; 2001).

Nas culturas de colaboração, as relações de trabalho entre professores tendem a seguir alguns princípios; baseiam-se no diálogo e na ação, fornecem aos professores feedback que os levam a refletir sobre a prática profissional. Para Day (2005, p. 232), a colaboração supõe uma negociação cuidadosa de confiança e comunicação eficaz, em que ambas as partes são aprendizes em um contexto reforçado pelo diálogo profissional. Em contextos de colaboração, os professores são encorajados a correr riscos, a diversificar suas estratégias de ensino, a enfrentar as mudanças como um processo de aperfeiçoamento contínuo (Day, 2005). 
A colaboração é destacada também por Michael Fullan ao afirmar que a capacidade de colaborar em pequena e grande escala está se tornando um dos requisitos básicos da sociedade pós-moderna, e por Hilda Borko, ao enfatizar as possibilidades da colaboração para o crescimento do professor e do coletivo escolar. A colaboração possibilita a aprendizagem profissional, que consequentemente, melhora o desempenho docente (Fullan, 1995; Desimone, 2011), assim como "promove a reflexão, a aprendizagem profissional e a associação entre as diferentes destrezas, a colaboração é um princípio crucial da aprendizagem organizacional" (Hargreaves, 1995, p. 279).

Hilda Borko, por sua vez, pontua que a pesquisa sobre comunidades de aprendizagem de professores normalmente explora características dos programas de desenvolvimento profissional, como o estabelecimento e manutenção de normas de comunicação e confiança, bem como as interações colaborativas que ocorrem quando grupos de professores trabalham juntos para examinar e melhorar sua prática (Borko, 2004). Para exemplificar, acrescenta que os resultados de pesquisas revelam que a colaboração entre pares e as conversas com colegas favorecem o aprofundamento do conhecimento disciplinar do conteúdo e sobre formas de ensiná-lo. Acrescenta, ainda, que as redes de trabalho, contextos de colaboração e parcerias constituem-se em contextos de aprendizagem profissional que apoiam a mudança nas práticas de ensino em suas próprias escolas e salas de aula (Borko, 1986; 2004).

Além disso, os teóricos associados a esta categoria evidenciam a relação entre as mudanças nas culturas profissionais, em especial no potencial da colaboração profissional, e a mudanças na prática. As culturas colaborativas concretizadas no interior das organizações educativas têm potencial para promover mudanças em nível micro (no interior das salas de aula) para o nível macro (das escolas para o nível dos sistemas de ensino), na medida em que o envolvimento e a interação de pequenas equipes podem fornecer uma base de compreensão e apoio ao nível das escolas e ampliar-se para os sistemas de ensino (Fullan, 1990; Hargreaves, 1995; Day, 2001). Os professores constituem coletivos comprometidos em melhorar o ensino, constituindose como grupos de apoio da prática uns dos outros. O trabalho em grupos, marcado pela confiança e apoio, fornece ao professor uma base para reflexão sobre a prática, permitindo que assumam riscos, resolvam problemas e entendam os dilemas da prática (Darling-Hammond, Hyler, \& Gardner, 2017).

Nesta perspectiva, o desenvolvimento profissional docente é especialmente influenciado pelos movimentos de rompimento de culturas de isolamento profissional estabelecidas, que se concretiza a partir do trabalho em colaboração, marcado pela interação horizontal e dialógica, apoio mútuo, partilha e negociação, que pode transcender os pequenos grupos ou instituições e alcançar agrupamentos escolares e redes de ensino.

\section{Mudanças na prática}

Uma importante dimensão do desenvolvimento profissional, bastante destacada na literatura consultada, especialmente em Thomas Guskey, Michael Fullan e Christopher Day, diz respeito às mudanças na prática. Por prática profissional docente nos referimos ao contexto mais alargado do ensino, transcendendo as fronteiras do trabalho em sala de aula com os alunos e envolvendo todas as demais atividades realizadas pelo professor, direta ou indiretamente relacionadas ao ensino. No âmbito deste contexto, o professor contextualiza os conhecimentos e valores desenvolvidos nos processos de formação, concretiza a articulação teoria e prática e promove ações que se voltam para o desenvolvimento cultural e intelectual dos alunos. Assim concebida, a prática profissional constitui-se em componente do desenvolvimento profissional na medida em que oportuniza ao professor concretizar a articulação entre teoria e prática (Clandinin, 1985; 1986), rever suas rotinas, refletir sobre esta prática (Day, 2001), assumir riscos e experimentar mudanças (Hargreaves, 1995).

Em uma análise sobre a natureza das mudanças na prática, Thomas Guskey afirma que o desenvolvimento profissional envolve mudanças na prática profissional do professor em três aspectos principais: mudanças nas práticas de salas 
de aula, mudanças em relação aos resultados de aprendizagem dos alunos e mudanças nas crenças e atitudes do professor (Guskey, 2002). As mudanças na sala de aula referem-se às rupturas com as formas cotidianas de promover o ensino e de gestão da sala de aula. As mudanças nos resultados de aprendizagem dos alunos faz alusão aos progressos dos alunos, ao seu desenvolvimento cognitivo. As mudanças nas crenças e atitudes caracterizam os movimentos de superação de valores, crenças, concepções e modos de agir que balizam o desenvolvimento do professor.

Thomas Guskey discute dois modelos teóricos contrapostos: o primeiro propõe que as mudanças nas crenças e atitudes do professor vêm primeiro e, portanto, mobilizam e sustentam as mudanças nas práticas de sala de aula e nos resultados de aprendizagem dos alunos na medida em que apoia-se na premissa de que os professores tornam-se comprometidos com novas práticas somente depois que eles tornam-se ativamente engajados a implementá-las (Crandall, 1983); o segundo modelo defende que as mudanças nas práticas de sala de aula antecedem as mudanças nas crenças e atitudes do professores, porque assume o princípio de que a experiência molda as crenças e atitudes (Guskey, 1985), assim como, em geral, as crenças e atitudes sobre o ensino são derivadas da experiência de sala de aula (Guskey, 2002; Clandinin, 1985; Fullan, 2000).

Os estudos de Michael Fullan corroboram a perspectiva de que as mudanças nas crenças e atitudes precedem as mudanças na prática. Para este autor, mudanças nas atitudes e crenças são mais suscetíveis de estimular mudanças na prática do que trazer mudanças na aprendizagem dos alunos. Considera, ainda, que o processo de mudança do professor é mais cíclico do que linear. Para Guskey (2002, p.5), "a questão é que a evidência de melhoria ou mudança positiva nos resultados de aprendizagem dos alunos geralmente precede, e pode ser um pré-requisito para, mudança significativa nas atitudes e crenças da maioria dos professores".

Um segundo fator importante que muitos programas de desenvolvimento profissional deixam de considerar é o processo de mudança de professor. As atividades de desenvolvimento profissional frequentemente são planejadas para iniciar mudanças nas atitudes, crenças e percepções dos professores. As ações de desenvolvimento profissional, por exemplo, muitas vezes tentam mudar as crenças dos professores sobre certos aspectos do ensino ou a conveniência de um currículo específico ou inovação educacional. Eles presumem que tais mudanças nas atitudes e crenças dos professores levarão a mudanças especiais em seus comportamentos e práticas em sala de aula, o que, por sua vez, resultará em um melhor aprendizado dos alunos (Guskey, 1997; 2002).

Por fim, Guskey e Huberman, propõem uma discussão sobre as implicações desses modelos teóricos para o desenvolvimento profissional do professor. Argumentam que a mudança é um processo gradual e difícil para o professor, por que aprender a ser proficiente em algo novo e atribuir significado diferente para as coisas que faz requer tempo e esforço, bem como a disponibilidade para assumir riscos. Aprender a ser proficiente em algo novo e encontrar significado em uma nova maneira de fazer as coisas, ou seja, promover mudanças na prática requer tempo e esforço. Ou seja, os professores tornam-se comprometidos com as novas práticas somente após terem se engajado ativamente em usá-las em suas salas de aula (Guskey e Huberman, 2002).

Esses autores acrescentam que é necessário apoio para ajudar o professor a tolerar a ansiedade advinda de possíveis falhas na concretização de novas práticas, e que a pressão é essencial para se iniciar uma mudança ou experimentar uma nova prática quando há resistência entre professores (Guskey \& Huberman, 2002). Consideram, ainda, que o ensino e a aprendizagem são influenciados por uma multiplicidade de variáveis contextuais e situacionais, tais como as reformas educacionais e as condições emocionais do professor (Guskey, 1997).

Portanto, a mudança na prática é um processo que, por um lado, pressupõe do professor a capacidade de promover a articulação entre teoria e prática e, por outro, propicia essa articulação. Ou seja, em seu ponto de partida, a mudança na prática emerge da superação da dicotomia entre teoria e prática profissional, na medida em que o professor busca ancorar teoricamente 
a sua prática e refletir sobre esta prática pela perspectiva da teoria. Por outro lado, as mudanças na prática, em seu horizonte, podem estabelecer novas relações entre teoria e prática mediante processos de reflexão, ancoradas em bases teóricas consistentes, sobre as práticas realizadas.

\section{Síntese do Quadro Teórico Esboçado e Discussão}

A partir do estudo realizado, que culminou na constituição do quadro teórico aqui apresentado, sistematizamos diversos aspectos inerentes a cada uma das dimensões do desenvolvimento profissional abordadas, conforme mostra a figura abaixo.

Figura 2: Dimensões do desenvolvimento profissional docente e seus aspectos constituintes.

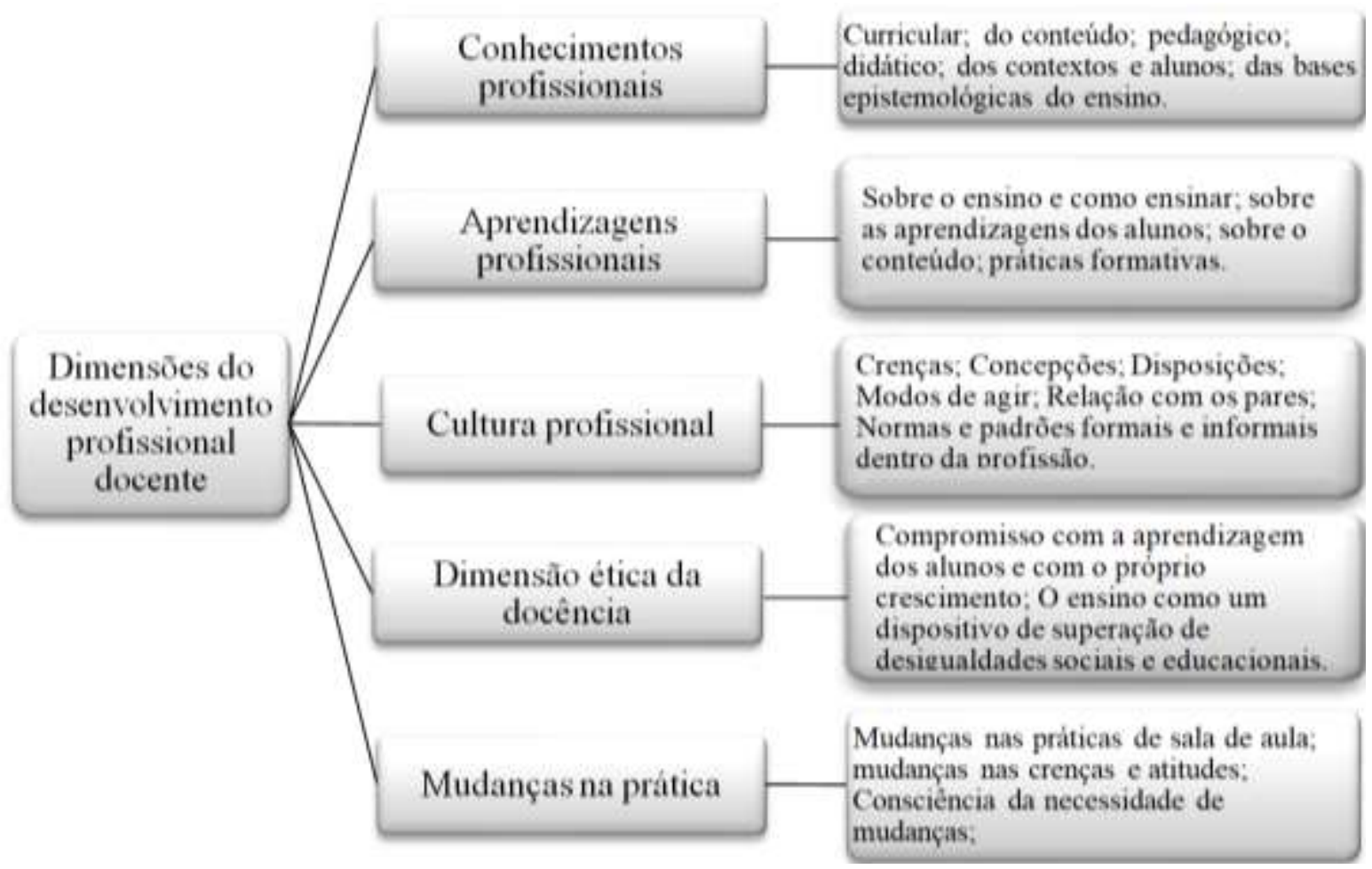

Fonte: Elaborado pela autora.

A análise mostrou que o desenvolvimento profissional assume natureza dinâmica e processual, baseado na apropriação de novos conhecimentos e aprofundamento de conhecimentos previamente adquiridos, na realização de aprendizagens profissionais de distinta natureza, na promoção de rupturas na cultura profissional e concretização da colaboração profissional, na disponibilidade para experimentar novas práticas e na tomada de consciência da dimensão ética do ensino. Assim entendido, caracteriza um processo contínuo ao longo da trajetória do professor, tornando-se essencial a busca por programas e atividades que permitam a ampliação e revisão de práticas, a melhoria das crenças, disposições e conhecimentos, favorecendo o crescimento pessoal e profissional do professor. Ou seja, o desenvolvimento profissional pressupõe aprendizagens profissionais e rupturas na cultura profissional, as quais oportunizam mudanças na prática. Tais mudanças são alimentadas por um elemento de base: a reflexão sobre a docência e seus processos intervenientes.

De acordo com Shulman (2004), a reflexão é a chave para o aprendizado e desenvolvimento do professor. Porém, de acordo com Guskey (2002), as mudanças na prática são influenciadas pelas atitudes e crenças do professor, sendo estas moldadas pelo contexto e pela experiência profissional cotidiana. Deste modo, os programas de desenvolvimento profissional 
precisam constituir-se em esforços sistemáticos envidados para promover mudanças nas práticas dos professores em sala de aula, em suas atitudes e crenças e nos resultados de aprendizagem dos alunos (Guskey, 2002).

Além disso, a superação do individualismo profissional em detrimento do trabalho em colaboração pode ser um meio eficiente de mudança educacional na medida em que fornece apoio e confiança para os professores assumirem riscos, o que pode resultar em melhoria dentro e fora do contexto escolar (Hargreaves, 1995; 2003), oportunizando ao professor agir como sujeito ativo e autônomo na prática que realiza (Clandinin, 1985; 1986).

O desenvolvimento profissional docente é um processo que emerge mediante a necessidade do professor manter o propósito e o sentido da docência (Desimone, 2009). Este processo é condicionado pela capacidade do professor rever as rotinas profissionais que balizam o seu desenvolvimento, aspecto este que pressupõe a capacidade de reflexão crítica sobre a sua prática e os fins da educação, bem como a concretização da articulação entre teoria e prática. A articulação teoria e prática compreende a relação entre ensino e aprendizagem, pois o modo como ocorre o primeiro implica formas distintas, às vezes desiguais, de aprendizagem. Portanto, ao planejar o ensino é preciso ter em mente o objetivo de aprendizagem que se quer alcançar (Crandall, 1983).

Em uma perspectiva de articulação das dimensões que sustentam e orientam o desenvolvimento profissional do professor, Clandinin $(1985 ; 1986)$ enfatiza que o conhecimento dos professores é constituído de um conjunto de convicções e significados que surge da experiência pessoal e social e que se expressam nas ações, pressupondo uma relação entre teoria e prática. É um conhecimento que vai sendo construído pela convergência de várias aprendizagens (dimensão teórica, dimensão experiencial, dimensão afetiva e outras) à medida que o profissional vai confrontando-as com a prática real e as internaliza em suas ações. Tais aprendizagens são construídas inicialmente nas primeiras experiências escolares e acompanham a trajetória profissional do professor em vista da natureza dinâmica e complexa dos contextos em que atuam. Assim, o desenvolvimento profissional docente "constitui-se com uma área ampla ao incluir qualquer actividade ou processo que tenta melhorar destrezas, atitudes, compreensão ou actuação em papéis actuais ou futuros" (Fullan, 1990, p. 3).

Nesta perspectiva, as ações formativas precisam oportunizar ao professor espaço para refletir, partilhar, aprofundar e (re)significar conhecimentos, ampliar crenças e disposições, experimentar novas práticas (Hargreaves, 1995), o que significa que precisam estar engajados na sua aprendizagem profissional e comprometidos com a prática que realizam e com o desenvolvimento dos alunos (Darling-Hammond, 1997; 1999; 2000). Essas atividades vinculam a aprendizagem profissional individual e pessoal à aprendizagem que também é colegial e comunitária (Darling-Hammond, 2000), na medida em que oportunizam a constituição de redes, comunidades de aprendizagem de professores (Borko, 2004; 2012). Essas redes oferecem aos professores oportunidades de crescimento profissional com potencial para favorecer mudanças nas escolas e nas redes de ensino, pois o apoio dos colegas e a confiança os encorajam a assumir riscos (Fullan 1990; Hargreaves, 1995).

Em síntese, o desenvolvimento profissional consolida-se como um processo dinâmico, flexível e contínuo na medida em que as aprendizagens profissionais concretizadas no contexto do trabalho colaborativo e integrado de equipes de professores, favorece o aprofundamento e significação dos conhecimentos basilares à docência, assim como a compreensão da dimensão ética da docência. Estas dimensões, interagindo de forma complementar, favorecem mudanças na prática profissional do professor e nas culturas profissionais, especialmente na superação das formas individualizadas de realizar o trabalho docente e no isolamento que marca a profissão docente, oportunizando mudanças na prática de sala de aula e rupturas nas culturas profissionais balizadoras do crescimento do professor.

\section{Considerações Finais}

O desenvolvimento profissional envolve a formação inicial, as atividades profissionais cotidianas do professor, suas 
vivências pessoais, suas crenças e disposições, os elementos da cultura profissional, assim como os diversos dispositivos de formação vivenciados ao longo da carreira (cursos frequentados, participação em eventos, socialização de experiências de sala de aula e reflexão sobre a docência, participação em associações de professores), promovendo o crescimento pessoal e profissional do professor e fomentando mudanças na prática. Esse processo é dinamizado e concretizado mediante a consolidação de uma base consistente de conhecimentos inerentes à docência; a realização de aprendizagens profissionais ao longo da carreira; à concretização de mudanças na cultura profissional das instituições educativas, especialmente na concretização de formas de trabalhar colaborativamente; à compreensão da dimensão ética da docência, impondo ao professor a necessidade de ser profissional, moral e eticamente responsável.

Entretanto, esse processo de desenvolvimento pode abranger outras dimensões, outras categorias que podem favorecer o crescimento pessoal e profissional do professor, aspecto este que sinaliza a necessidade de estudos complementares para evidenciar novas dimensões e compreendê-las, ampliando, assim, o quadro teórico apresentado neste estudo. Além disso, há a necessidade de estudos complementares que possam examinar o modo como estas dimensões se relacionam entre si, promovendo o desenvolvimento do professor e, também, quais aspectos sustentam essas dimensões. Por fim, é necessário compreender como as particularidades do contexto de trabalho do professor e as diretrizes educacionais podem influenciar esse processo de desenvolvimento. Fica, portanto, estas sugestões de estudos complementares.

\section{Agradecimentos}

Agradecemos ao CNPq pelo financiamento (Processo número 305476/2020-3).

\section{Referências}

Ball, D. L. (1993). With an eye on the mathematical horizon: Dilemmas of teaching elementary school mathematics. Elementary School Journal, 93, $373-397$.

Ball, D. L., Heather, H., \& Bass, H. (2005). Knowing Mathematics for Teaching. American Educator, 14-46.

Ball, D. L., Thames, M. H., \& Phelps, G. (2008). Content knowledge for teaching: What makes it special? Journal of Teacher Education, New York, 59(5), $389-407$.

Bardin, L. (2003). Análise de conteúdo. Lisboa: Edições 70.

Borko, H. (1986). Clinical Teacher Education: The Induction Years. In J.A.E.S. Hofman (Ed). Reality and Reform in Clinical Teacher Education (pp. 45-64). New York: Random House.

Borko, H. (2004). Professional Development and Teacher Learning. Educational Researcher, 33(8), 3-15.

Borko, H., \& Putnam, R.T. (1996). Learning to teach. In D. C. Berliner \& R. C. Calfee (Eds.), Handbook of educational psychology (pp. 673-708). Macmillan Library Reference USA; Prentice Hall International.

Clandinin, D. J. (1985). Personal practical knowledge: a study of teacher's classroom images. Curriculum Inquiry, 14(4), 361-385.

Clandinin, D.J. (1986). Classroom practice, teacher images in action. Londres: The Falmer Press.

Clandinin, D. J. \& Connelly, F. M. (1987). Teachers' personal knowledge: what counts as 'personal' in studies of the personal. Curriculum Inquiry, 19(6), 487-500.

Clandinin, D. J. \& Connelly, M. (1988). Studying Teachers' Knowledge of Classroom: Collaborative research, ethics, and the negotiation of narrative. The Journal of Educational Thought, 22 (2A/special issue), 269-282.

Clandinin, D.J. \& Connelly, M. (1996). Teacher's Professional Knowledge Landscapes: Teacher's stories, stories of teachers, school stories, stories of schools. Educational Researcher. 25 (3), 24-30.

Crandall, D. (1983). The teacher's role in school improvement. 41(3), 6-9.

Darling-Hammond, L. (1997). Doing what matters most: investing in qualiy teaching. New York: National Commission on Teanching ad Americas'Future.

Darling-Hammond, L. (2000). Teacher Quality and Student Achievement: A Review of State Policy Evidence. Educational Policy Analysis Archives, 8(1).

Darling-Hammond, L. (2001). El derecho de aprender. Crear buenas escuelas para todos. Barcelona: Ariel. 
Darling-Hammond, L., Hyler, M. E., \& Gardner, M. (2017). Effective Teacher Professional Development. Palo Alto, CA: Learning Policy Institute.

Darling-Hammond, L., Wei, R. C., Andree, A., Richardson, N., \& Orphanos, S. (2009). Professional learning in the learning profession, 9. Washington, DC: National Staff Development Council.

Day, C. (1999). Developing Teachers. The Challenges of Lifelong Learning. London: Falmer Press.

Day, C. (2001). Desenvolvimento Profissional de Professores. Porto, Portugal: Porto Editora.

Day, C. Formar Docentes: cómo, cuándo y en qué condiciones aprende el profesorado. Madrid: Narcea. 2005.

Day, C. Pasión por enseñar: La identidad personal y profesional del docente y sus valores. Barcelona: Narcea, 2006.

Desimone, L. M. (2009). Improving impact studies of teachers' professional development: Toward better conceptualizations and measures. Educational researcher, 38(3), 181-199.

Desimone, L. M. (2011) A primer on effective professional development. Journal Phi Delta Kappan. 92(6). 68-71.

Erickson, F. (1986). Qualitative Methods in Research on Teaching. In Handbook of Research on Teaching (pp. 119-161). ${ }^{\text {rd }}$ ed. New York: Macmillan.

Feiman-Nemser, S. (2001). From Preparation to Practice: Designing a Continuum to Strengthen and Sustain Teaching. Teachers College Record, 103(6), 1013-1055.

Ferreira, L. G. (2020). Desenvolvimento profissional docente: percursos teóricos, perspectivas e (des)continuidades. Educação em Perspectiva, 1, 01-18.

Fullan, M. (1985). Change processes and strategies at the local level. Elementary School Journal, 85, 391-421.

Fullan, M. (1990). Staff Development Innovation and Institutional Development. In B. Joyce (ed.), School Culture Through Staff Development (pp. 3-25). Virginia: ASCD.

Fullan, M. (1993). The Professional Teacher Why Teachers Must Become Change Agents. Educational Leadership, 50(6).

Fullan, M. (1995). The school as a learning organization. Theory Into Practice, 34(4), 230-235.

Fullan, M. (2001). Leading in a Culture of Change. San Francisco: Jossey-Bass/Wiley.

Fullan, M. (2007). The new meaning of educational change, 4th edition, 35. New York City, NY: Teachers College, Columbia University.

Guskey, T. (1985). Staff development and teacher change. Educational Leadership, 42(7), 57-60.

Guskey, T. (1997). Attitude and Perceptual Change in Teachers. International Journal of Educational Research, 13(4), 439-453.

Guskey, T. (2002). Professional Development and Teacher. Teachers and Teaching: theory and practice, 8(3/4), 381-391.

Guskey, T., \& Huberman, M. (1995). Professional Development in Education. New York, EUA: Teacher College Press.

Hargreaves, A. (1995). Development and Desire: A postmodern perspective. (pp. 9-34.). In: Guskey, T.; Hubermann, M.(eds). Professional Development in Education: New perspective \& practices.

Hargreaves, A. (2003). O Ensino na Sociedade do Conhecimento: a educação na era da insegurança. Porto: Porto Editora. 287 p.

Hargreaves, A., \& Fullan, M. (2012). Professional capital: Transforming teaching in every school. Teachers College Press.

Hill, H., Rowan, B., \& Ball, D. L. (2005). Effects of teachers' mathematical knowledge for teaching on student achievement. American Education Research Journal, 42(2), 371-406.

Hill. H.C. (2010). The nature and predictors of elementary teachers' Mathematical Knowledge for Teaching. Journal for Research in Mathematics Education, $41(5), 513-545$.

Hill, H.C. (2012). The nature and effects of middle school mathematics teacher learning experiences. Teachers' College Record.

Hill, H.C., Ball, D.L., \& Schilling, S.G. (2008). Unpacking “Pedagogical Content Knowledge”: Journal for Research in Mathematics Education, 39, 372-400.

Hill, H. C. \& Ball, D. L. (2004). Learning mathematics for teaching: Results from California's mathematics professional development institutes. Journal for Research in Mathematics Education, 35(5), 330-351.

Hobold, M.S. (2018). Desenvolvimento profissional dos professores: aspectos conceituais e práticos. Práxis Educativa, 13(2), 425-442.

Little, J. (1993). Teachers' Professional Development in a Climate of Educational Reform. Educational Evaluation and Policy Analysis, 15, $129-151$.

Marcelo, Carlos (2009). Desenvolvimento Profissional Docente: passado e futuro. Sísifo. Revista de Ciências da Educação, 08, 7-22.

Petticrew, M. \& Roberts, H. (2006). Systematic Reviews in the Social Sciences: A Practical Guide. Oxford: Blackwell.

Richit, Adriana (2021). Desenvolvimento Profissional em Estudos de Aula: expectativas e perspectivas de professores participantes. In A.S. Loss, A. \& A.P. Loro (Orgs), Estudos interdisciplinares: debates e reflexões (pp. 219-236). Curitiba: CRV. 
Research, Society and Development, v. 10, n. 14, e342101422247, 2021

(CC BY 4.0) | ISSN 2525-3409 | DOI: http://dx.doi.org/10.33448/rsd-v10i14.22247

Richit, Adriana (2020). Estudos de Aula na Perspectiva de Professores Formadores. Revista Brasileira de Educação, 62 (3), 1-24.

Richit, A. \& Tomkelski, M.L. (2020). Aprendizagens profissionais de professores de matemática do ensino médio no contexto dos estudos de aula. Acta Scientiae, Revista de Ensino de Ciências e Matemática, 22(3), 2-27.

Silva, J. C., Ghedin, E. L., Eda, A. S (2017). The concepts of professional development, professionalism, formative needs and teacher identity in the discourse of basic education teachers of two Brazilian municipalities. Research, Society and Development, 5(2), 124-137.

Shulman, L. S. (1986). Those Who Understand. Educational Researcher, 15(2), 4-14.

Shulman, L. S. (1987). Knowledge and Teaching. Harvard Educational Review, 57, 1-23.

Shulman, L. (2004). The Wisdom of Practice: Essays on Teaching, Learning. San Francisco: Jossey-Bass. 